\title{
A Fuzzy Decision Model of Maintenance Strategy for Key Signalling Equipments of Urban Rail Transit
}

\author{
Zhangyang Li ${ }^{1,2, a}$, Wei $\mathrm{Nai}^{2, b, *}$, Yi Yu ${ }^{2, \mathrm{c}}$, Shaoyin Wang ${ }^{3, \mathrm{~d}}$ and Decun Dong, \\ ${ }^{1}$ The Key Laboratory of Road and Traffic Engineering, Ministry of Education, Tongji University, \\ Shanghai, China \\ ${ }^{2}$ The Cooperative Center for Maglev and Rail Transit, Tongji University, Shanghai, China \\ ${ }^{3}$ Department of Electronics and Information Engineering, Tongji Zhejiang College, Jiaxing, \\ Zhejiang, China \\ a lizhangystanden@qq.com, ${ }^{b}$ alexni@tongji.edu.cn, ${ }^{\mathrm{c}}$ 12164@tongji.edu.cn, ${ }^{\mathrm{c}}$ 82730@tongji.edu.cn, \\ eddc@tongji.edu.cn, \\ *corresponding author
}

Keywords: Urban rail transit, signalling equipments, maintenance time, maintenance strategy, fuzzy decision model, Vague set.

\begin{abstract}
Rail transit signalling system is a safety critical system, the faults which happen in key equipments of such system could have a negative effect on trains in operation, especially during rush hours. At present, maintenance strategies of those key equipments in general cannot reflect the maintenance demands accurately, for they cannot, on some level, take all the deterministic and non-deterministic factors into consideration. In this paper, a fuzzy decision model which determines the maintenance strategy of key equipments in rail transit signalling system based on Vague sets fuzzy reasoning has been proposed, and based on a case study of Shanghai Metro Line 6, the proposed decision-making model has been proved to be able to not only determine the required maintenance event of equipments, but built the corresponding countermeasure sets as well.
\end{abstract}

\section{Introduction}

As part of the older metro lines in those cities like Shanghai which has a relatively longer history in urban rail transit development, many key equipments of signalling system in service in those older metro lines have already met the end or even surpass their length of designed physical life. In practice, some components of those key equipments have already been replaced several years ago for the sake of operation safety, while some others may still be used in everyday operation for their working status are proved to be acceptable [1]. Consider that the signalling system is a safety critical system in urban rail transit, the faults which happen in key equipments of such system could have a negative effect on trains in operation, such as causing trains stop or other related loss, especially during rush hours, it is necessary to do a in-depth analysis on the maintenance strategy 
for those key equipments, and to find a reasonable maintenance strategy with a proper theory algorithm supported. In this way, system reliability and fault pattern can be mastered by the operators, and the way to do the maintenance work for key equipments can be optimized [2].

The maintenance strategy mentioned above aims to analyze and decide which kind of maintenance means should be adopted and when to repair key equipments, so as to help the operators to do the targeted maintenance work within the shortest time and the lowest cost [3]. As for the maintenance work for key equipments in older metro lines, active and preventive maintenance strategy is sure to be more suitable, for the maintenance tasks arranged by such strategy would cause the minimum impact on the everyday operation. Consider that there are many components in key equipments of the signalling system, each component has its own role in train operation, the working status of different may have different impact on the whole function of the signalling system. Moreover, the working status of those components as well as key equipments may have mutual interactions, sometimes it is hard to do a clear evaluation for the very maintenance work of a certain equipment [4].

During recent years, fuzzy set theory has been widely used in decision-making process such as strategy determination, for it can help to deal with uncertainty properties of a certain system being analyzed by employing fuzzy linguistic expression in describing working status and mutual interaction information of system elements. Gau et al. (1993) have proposed the concept of Vague Set, it is characterized by two aspects including supportive and opposite evidences, and it has a stronger ability in dealing with uncertain information compared with traditional fuzzy set theory [5]. Based on Vague Set theory, extended technique for order preference by similarity to an ideal solution (TOPSIS) method has been proposed [6-7]. Zhou et al. (2006) have made a clear definition of the distance between Vague Sets, and have proposed a multi-criteria fuzzy TOPSIS method [8]. Liu et al. (2009) have proposed the concept of interval-value Vague Set, defined the scoring function and precision function of interval-value Vague Set, and proposed the expanded TOPSIS method with both attribute weights and attribute value belongs to the value of interval-value Vague Set [9].

From the literature review above on the studies of fuzzy multi-criteria decision making problem based on Vague Set theory, it can be seen that researchers tend to use large interval in dealing with fuzzy information, and thus make the uncertainty in decision making be increased by making the value of interval cover the whole range, there is always a lack of fuzzy reasoning analysis on original data under the TOPSIS framework. In this paper, a fuzzy decision model which determines the maintenance strategy of key equipments in rail transit signalling system based on Vague sets fuzzy reasoning has been proposed, and based on a case study of Shanghai Metro Line 6, the proposed decision-making model has been proved to be able to not only determine the required maintenance event of equipments, but built the corresponding countermeasure sets as well.

\section{Basic Concepts of Vague Sets}

\subsection{Linguistic Evaluation Sets and Vague Interval-Value Numbers}

Linguistic description is an effective way to handle the problem which is hard to be quantified. The elements of the evaluation sets can always be formed by $l$ words in natural language $(l$ is an odd number), which can be expressed as $S=\left(S_{0}, S_{1}, \ldots, S_{l-1}\right)$. In later discussion of this paper, $l$ is set as 5 according to the evaluating habits for key equipments, therefore, the evaluation set $S$ can be described as $S=$ (very poor, poor, medium, good, very good). In order to do the decision making based on Vague Set, the qualitative linguistic evaluation set mentioned above have to be converted into Vague interval-value numbers. In such Conversion, hesitancy in evaluation should be considered so as to make the decision process be more closer to the reality [10]. 
For the conversion process here in this paper, the reference value of affirmation membership grade of each linguistic variable is given at first, then the realistic affirmation membership grades can be calculated according to the linguistic evaluation variables given by experts and the corresponding hesitancy, as shown in Table 1, where variables $\alpha$ and $\beta$ represent the upper bound and lower bound of hesitancy. For example, if the linguistic evaluation variable for status "Good" given by experts is $\mathrm{G}(0.1)$, then the converted Vague interval-value number is $[0.7-\alpha \times \pi, 0.7+\beta \times$ $\pi]=[0.65,0.75]$.

Table 1 Linguistic variables and their corresponding Vague interval-value number.

\begin{tabular}{|c|c|c|}
\hline Linguistic variable & Vague interval-value number & Values of $\alpha, \beta$ \\
\hline Very Poor (VP) & {$[0.1-\alpha \times \pi, 0.1+\beta \times \pi]$} & $\alpha=0, \beta=1$ \\
Poor (P) & {$[0.3-\alpha \times \pi, 0.3+\beta \times \pi]$} & $\alpha=\beta=0.5$ \\
Medium (M) & {$[0.5-\alpha \times \pi, 0.5+\beta \times \pi]$} & $\alpha=\beta=0.5$ \\
Good (G) & {$[0.7-\alpha \times \pi, 0.7+\beta \times \pi]$} & $\alpha=\beta=0.5$ \\
Very Good (VG) & {$[0.9-\alpha \times \pi, 0.9+\beta \times \pi]$} & $\alpha=1, \beta=0$ \\
\hline
\end{tabular}

\subsection{Situation and Vague Effect Vector}

Definition 1: If $a_{i}$ is an event to be handled, $b_{j}$ is the $j$ th countermeasures for event $a_{i}$, then the combination of $a_{i}$ and $b_{j}$ is defined as situation, which can be expressed as $S_{i j}$, recorded as

$$
S_{i j}=\left(a_{i}, b_{j}\right)
$$

Definition 2: If $u_{i j}{ }^{(k)}$ is the Vague effect value of situation $S_{i j}$ under target $k$, then the Vague effect vector $u_{i j}$ corresponds to situation $S_{i j}$ is

$$
u_{i j}=\left(u_{i j}{ }^{(1)}, u_{i j}^{(2)}, \ldots, u_{i j}^{\left({ }^{(k)}\right.}, \ldots, u_{i j}{ }^{(p)}\right)=\left\{\left[u_{i j l}{ }^{(1)}, u_{i j u}{ }^{(1)}\right],\left[u_{i j l}{ }^{(2)}, u_{i j u}{ }^{(2)}\right], \ldots,\left[u_{i j l}{ }^{(p)}, u_{i j u}{ }^{(p)}\right]\right\}
$$

where $i=1,2, \ldots, n, n$ is the total number of events to be handled; $j=1,2, \ldots, m, m$ is the total number of decision made, $p$ is the total number of decision target.

\subsection{Determination of Ideal Optimal Vague Effect Vector}

Definition 3: If $u_{i 0 j 0}{ }^{(k)}$ is the optimal Vague effect value of situation $S_{i j}$ under target $k$, then the optimal Vague effect vector $u_{i 0 j 0}$ corresponds to situation $S_{i j}$ is

$$
u_{i j}=\left(u_{i 0 j 0}^{(1)}, u_{i 0 j 0}^{(2)}, \ldots, u_{i 0 j 0}^{(k)}, \ldots, u_{i 0 j 0}^{(p)}\right)=\left\{\left[u_{i 0 j 0 l}^{(1)}, u_{i 0 j 0 u}^{(1)}\right],\left[u_{i 0 j 0 l}^{(2)}, u_{i 0 j 0 u}^{(2)}\right], \ldots,\left[u_{i 0 j 0 l}^{(p)}, u_{i 0 j 0 u}^{(p)}\right]\right\}
$$

In practice, each decision making problem has different characteristics, and might be affected by different requirements, and the ideal optimal Vague effect vector can be determined according to

$$
u_{i 0 j 0}^{(k)}=\left\{\left(\max _{1 \leq i \leq n} u_{i j}^{(k)} \mid j \in J_{1}\right),\left(\min _{1 \leq i \leq n} u_{i j}^{(k)} \mid j \in J_{2}\right),\left(u_{0} \mid j \in J_{3}\right)\right\}
$$

where $J_{1}$ is the benefit index set, the bigger the better; $J_{2}$ is the cost index set, the smaller the better; $J_{3}$ is the moderated value index set, its value is $u_{0}$.

\subsection{Calculation of Relative Proximity}

Based on the idea of TOPSIS method, the distance between a certain situation and the positive ideal solution (PIS) / negative ideal solution (NIS) can be calculated by equation (5) and (6), here the PIS and NIS correspond to the positive and negative ideal Vague effect vector [11]. It should be pointed out that Euclidean distance is used distance calculation in equation (5) and (6).

$$
s_{i}^{*}=\sqrt{\frac{1}{2 n} \sum_{j=1}^{n} w_{j}\left[\left(t_{i j}-t_{i j}^{*}\right)^{2}+\left(f_{i j}-f_{i j}^{*}\right)^{2}+\left(\pi_{i j}-\pi_{i j}^{*}\right)^{2}\right]}
$$




$$
s_{i}^{-}=\sqrt{\frac{1}{2 n} \sum_{j=1}^{n} w_{j}\left[\left(t_{i j}-t_{i j}^{-}\right)^{2}+\left(f_{i j}-f_{i j}^{-}\right)^{2}+\left(\pi_{i j}-\pi_{i j}^{-}\right)^{2}\right]}
$$

And the relative proximity $C_{i}$ between Vague Sets can be calculated as

$$
C_{i}=s_{i}^{*} /\left(s_{i}^{*}+s_{i}^{-}\right)
$$

\section{Determination of Maintenance Strategy Based on Vague Situation}

\subsection{Determination of Maintenance Strategy Set and Situation Set}

The maintenance and management subsystem (MMS) in operation control system (OCS) in urban rail transit can help the operator to collect information of equipment characteristics. And in practice, 5 different maintenance strategies may be adopted by field workers, namely $b_{1}$ : back (after the faults) maintenance $(\mathrm{BM}), b_{2}$ : reliability calculation based maintenance (RCM), $b_{3}$ : condition based maintenance (CBM), $b_{4}$ : fixed-time based maintenance (TBM), and $b_{5}$ : preventive maintenance (PM). Thus the maintenance strategy can be recorded as $B=\left\{b_{1}, b_{2}, b_{3}, b_{4}, b_{5}\right\}$, and its corresponding situation set is

$$
S=\left\{s_{1 j}=\left(a_{1}, b_{j}\right) \mid b_{j} \in B\right\}=\left\{s_{11}, s_{12}, s_{13}, s_{14}, s_{15}\right\}
$$

where $a_{1}$ is the fault maintenance event for key equipment in urban rail transit.

\subsection{Strategy Evaluation Indices Set}

Consider that the goal of maintenance strategy determination is to help enhance the utilization of key equipments and their reliability, economical factors should be considered in the determination process. Here is this paper, safety, reliability, maintainability, economy, and monitoring factors are employed as indices to evaluate the maintenance strategy. To be specific, safety factor describes the degree affected by the fault of a certain key equipment on people, other equipments and environment; reliability factor describes the ability of a certain key equipment to finish specified task within certain time and under certain conditions; maintainability factor describes the ability of a certain key equipment to recover its function within certain time and under certain repairing conditions; economy factor describes the costs of repairing work and operation lost caused by certain equipment fault; monitoring factors describes the cost of instruments, methods for certain key equipment.

If the weight of those 5 indices above are $0.30,0.25,0.15,0.2$ and 0.1 , and 3 different types of experts including $d_{1}$ : on-site maintenance workers, $d_{2}$ : managers of operation department, $d_{3}$ : chief leaders of the rail transit operator, are invited to give linguistic evaluation variables. The authority weight are $0.4,0.32$ and 0.28 for $d_{1}, d_{2}$ and $d_{3}$ respectively.

\subsection{Determination of PIS and NIS Vague Effect Vectors}

Vague effect values $u_{1 j}{ }^{(k)}(j=1,2, \ldots, 5)$ correspond to situation $S_{1 j}$ under the evaluation target $k$ can be described as

$$
u_{1 j}=\left(u_{1 j}^{(1)}, u_{1 j}^{(2)}, \ldots, u_{1 j}^{(5)}\right), j=1,2, \ldots, 5
$$

As all of the 5 evaluation target are benefit index, thus, according to equation (4), the optimum Vague effect value and negative Vague effect value PIS, NIS of situation $S_{1 j}$ can be calculated as:

$$
\begin{gathered}
P I S=\left\{\max \left[u_{1 j l}^{(1)}, u_{1 j u}^{(1)}\right], \max \left[u_{1 j l}^{(2)}, u_{1 j u}^{(2)}\right], \ldots, \max \left[u_{1 j l}^{(5)}, u_{1 j u}^{(5)}\right]=\left\{\left[p_{1 l}^{+}, p_{1 u}^{+}\right],\left[p_{2 l}^{+}, p_{2 u}^{+}\right], \ldots,\left[p_{5 l}^{+}, p_{5 u}^{+}\right]\right\}\right. \\
N I S=\left\{\min \left[u_{1 j l}^{(1)}, u_{1 j u}^{(1)}\right], \min \left[u_{1 j l}^{(2)}, u_{1 j u}^{(2)}\right], \ldots, \min \left[u_{1 j l}^{(5)}, u_{1 j u}^{(5)}\right]=\left\{\left[p_{1 l}^{-}, p_{1 u}^{-}\right],\left[p_{2 l}^{-}, p_{2 u}^{-}\right], \ldots,\left[p_{5 l}^{-}, p_{5 u}^{-}\right]\right\}\right.
\end{gathered}
$$




\subsection{Maintenance Strategy Determination Based on Vague Situation}

The determination of maintenance strategy based on Vague situation can be done as the following steps: 1) determine the maintenance strategy set and the decision indices according to the maintenance regulations and on-site maintenance conditions, and obtain the original decision matrix are by linguistic evaluation variables given by experts; 2) convert the linguistic evaluation variables into Vague interval-value numbers according to Table 1, and construct the Vague matrix by considering the weights of experts; 3) determine the Vague effect vectors according to the evaluation indices, and obtain PIS and NIS Vague effect vectors according to equation (8); 4) calculate the longest distance between PIS and each situation, the shortest distance between NIS and each situation, and calculate the relative proximity according to equation (7); 5) select the optimal maintenance strategy by ranking the relative proximity. The steps can be illustrated as in Figure 1.

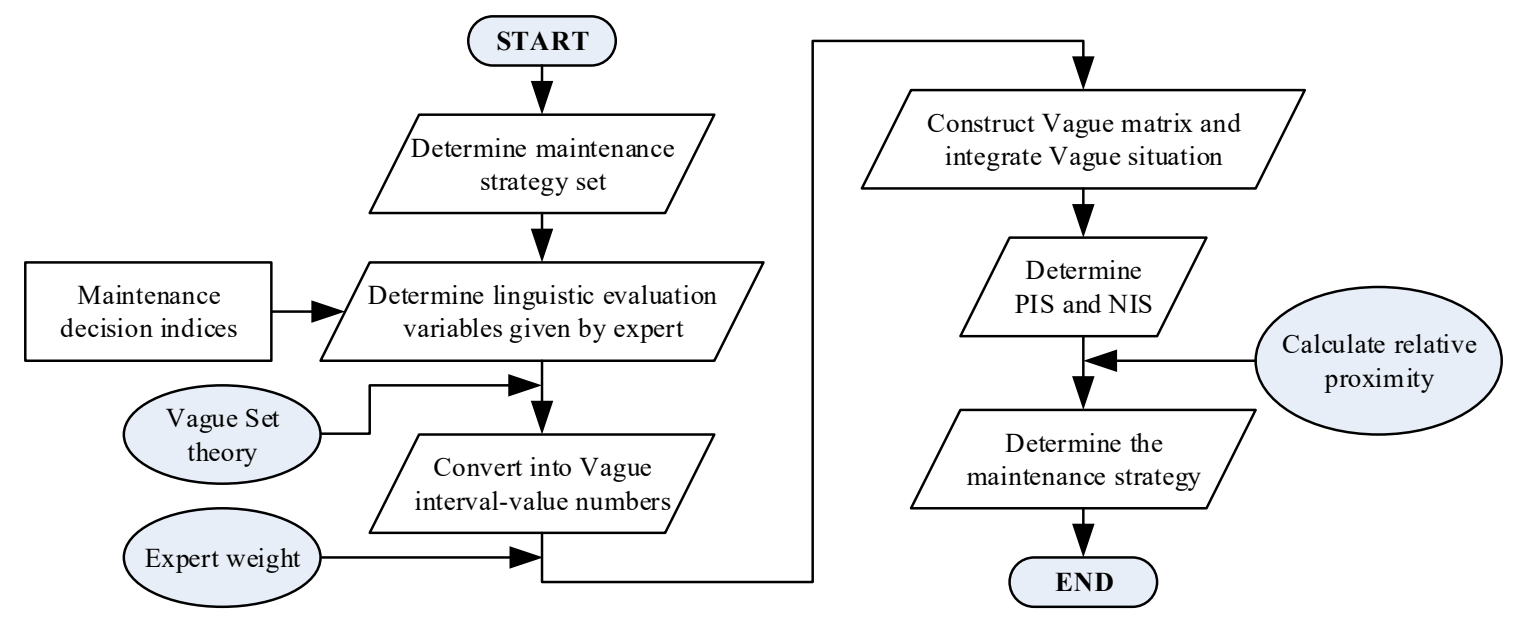

Figure 1 The decision making steps based on Vague situation.

\section{Case Study}

Shanghai Metro Line 6 is a urban rail transit line with its signalling system equipped by communication based train control (CBTC) system, the radio block center (RBC) can be seen as a key equipment in CBTC. As the line has been put into operation since 2007, components of RBC have already approached the end of their lifecycle, therefore, setting proper maintenance strategy for RBC is important for operation safety. For the RBC maintenance event set $a_{1}$, maintenance strategy set is $B=\left\{b_{1}, b_{2}, b_{3}, b_{4}, b_{5}\right\}$, and Vague situation set $S$ can be described as $S_{1 j}=\left\{\left(a_{1}, b_{j}\right) \mid b_{j}\right.$ $\in B\}=\left\{s_{11}, s_{12}, s_{13}, s_{14}, s_{15}\right\}$.

According to the maintenance decision indices, 3 types of experts mentioned in section 3 are then been organized to give linguistic variables, as shown in Table 2. Those linguistic variables can be converted into Vague interval-value number, and then the comprehensive Vague effect vector of maintenance strategy $S_{11}$ can be calculated out according to the expert weight, as shown in Table 3 . Similarly, $S_{12}$ to $S_{15}$ can also be calculated out. Then, according to equation (8), the Vague effect vector PIS and NIS can be calculated out, as shown in Table 4. Afterwards, the longest distance between PIS and each situation and the shortest distance between NIS and each situation according to the TOPSIS method, the relative proximity can then be calculated according to equation (7), as shown in Table 5. Through a ranking process, it can be seen that $S_{15}$ is the optimal Vague situation, therefore, PM strategy is arranged as the maintenance mode for RBC equipments. 
Table 2 Linguistic variables given by experts.

\begin{tabular}{|c|c|c|c|c|c|c|}
\hline Expert & Weight & $\begin{array}{c}\text { Safety } \\
(0.3)\end{array}$ & $\begin{array}{c}\text { Reliability } \\
(0.25)\end{array}$ & $\begin{array}{c}\text { Maintainability } \\
(0.15)\end{array}$ & $\begin{array}{c}\text { Economy } \\
(0.2)\end{array}$ & $\begin{array}{c}\text { Monitoring } \\
(0.1)\end{array}$ \\
\hline$d_{1}$ & 0.4 & $\mathrm{VG}(0.3)$ & $\mathrm{P}(0.1)$ & $\mathrm{P}(0.1)$ & $\mathrm{M}(0.1)$ & $\mathrm{P}(0.2)$ \\
$d_{2}$ & 0.32 & $\mathrm{VG}(0.2)$ & $\mathrm{P}(0.1)$ & $\mathrm{M}(0.2)$ & $\mathrm{P}(0.1)$ & $\mathrm{P}(0.1)$ \\
$d_{3}$ & 0.28 & $\mathrm{G}(0.1)$ & $\mathrm{P}(0.2)$ & $\mathrm{M}(0.3)$ & $\mathrm{P}(0.3)$ & $\mathrm{P}(0)$ \\
\hline
\end{tabular}

Table 3 Linguistic variables described in Vague interval-value numbers.

\begin{tabular}{|c|c|c|c|c|c|c|}
\hline Expert & Weight & $\begin{array}{c}\text { Safety } \\
(0.3)\end{array}$ & $\begin{array}{c}\text { Reliability } \\
(0.25)\end{array}$ & $\begin{array}{c}\text { Maintainability } \\
(0.15)\end{array}$ & $\begin{array}{c}\text { Economy } \\
(0.2)\end{array}$ & $\begin{array}{c}\text { Monitoring } \\
(0.1)\end{array}$ \\
\hline$d_{1}$ & 0.4 & {$[0.75,1]$} & {$[0.25,0.35]$} & {$[0.25,0.35]$} & {$[0.45,0.55]$} & {$[0.2,0.4]$} \\
$d_{2}$ & 0.32 & {$[0.8,1]$} & {$[0.25,0.35]$} & {$[0.4,0.6]$} & {$[0.25,0.35]$} & {$[0.25,0.35]$} \\
$d_{3}$ & 0.28 & {$[0.65,0.75]$} & {$[0.2,0.4]$} & {$[0.35,0.65]$} & {$[0.15,0.45]$} & {$[0.3,0.3]$} \\
$S_{11}$ & & {$[0.72,0.9]$} & {$[0.24,0.36]$} & {$[0.33,0.51]$} & {$[0.3,0.46]$} & {$[0.24,0.36]$} \\
\hline
\end{tabular}

Table 4 Vague situation effect of each maintenance strategy.

\begin{tabular}{|c|c|c|c|c|c|}
\hline & $\begin{array}{c}\text { Safety } \\
(0.3)\end{array}$ & $\begin{array}{c}\text { Reliability } \\
(0.25)\end{array}$ & $\begin{array}{c}\text { Maintainability } \\
(0.15)\end{array}$ & $\begin{array}{c}\text { Economy } \\
(0.2)\end{array}$ & $\begin{array}{c}\text { Monitoring } \\
(0.1)\end{array}$ \\
\hline$S_{11}$ & {$[0.72,0.9]$} & {$[0.24,0.36]$} & {$[0.33,0.51]$} & {$[0.3,0.46]$} & {$[0.24,0.36]$} \\
$S_{12}$ & {$[0.77,0.9]$} & {$[0.46,0.65]$} & {$[0.31,0.47]$} & {$[0.28,0.48]$} & {$[0.39,0.5]$} \\
$S_{13}$ & {$[0.8,0.9]$} & {$[0.61,0.74]$} & {$[0.27,0.46]$} & {$[0.61,0.74]$} & {$[0.46,0.67]$} \\
$S_{14}$ & {$[0.72,0.9]$} & {$[0.52,0.64]$} & {$[0.26,0.45]$} & {$[0.27,0.5]$} & {$[0.52,0.64]$} \\
$S_{15}$ & {$[0.68,0.81]$} & {$[0.58,0.71]$} & {$[0.53,0.63]$} & {$[0.56,0.85]$} & {$[0.64,0.76]$} \\
PIS & {$[0.8,0.9]$} & {$[0.61,0.74]$} & {$[0.53,0.63]$} & {$[0.61,0.85]$} & {$[0.64,0.76]$} \\
NIS & {$[0.6,0.77]$} & {$[0.24,0.36]$} & {$[0.26,0.45]$} & {$[0.27,0.46]$} & {$[0.24,0.36]$} \\
\hline
\end{tabular}

Table 5 Proximity result of each maintenance strategy based on TOPSIS.

\begin{tabular}{|c|c|c|c|c|c|}
\hline & $\begin{array}{c}\text { Safety } \\
(0.3)\end{array}$ & $\begin{array}{c}\text { Reliability } \\
(0.25)\end{array}$ & $\begin{array}{c}\text { Maintainability } \\
(0.15)\end{array}$ & $\begin{array}{c}\text { Economy } \\
(0.2)\end{array}$ & $\begin{array}{c}\text { Monitoring } \\
(0.1)\end{array}$ \\
\hline$S_{i}^{*}$ & 0.1338 & 0.089 & 0.0504 & 0.0504 & 0.0291 \\
$S_{i}^{-}$ & 0.0191 & 0.0731 & 0.1195 & 0.1195 & 0.1268 \\
$C_{i}$ & 0.875 & 0.549 & 0.549 & 0.297 & 0.187 \\
\hline
\end{tabular}

According to the analysis above, it can be seen that PM is the recommended maintenance strategy for RBC equipment in CBTC signalling system in Shanghai Metro Line 6, in practice, such maintenance strategy is just the strategy being employed in the maintenance department of the operator. Thus, the effectiveness of the method proposed in this paper can be verified.

\section{Conclusion}

Base on Vague Set and multi criteria fuzzy decision theory, in this paper, a fuzzy decision model has been proposed to give the recommended maintenance strategy for key equipments of the signalling system in urban rail transit. The proposed method has taken 5 qualitative evaluation indices including safety, reliability, maintainability, economy and monitoring factor into consideration, and can calculate out the corresponding Vague interval-value numbers of those 5 indices according to the linguistic variables given by experts, and can finally determine the optimal maintenance strategy by calculating the relative proximity of each maintenance strategy out. Case study shown in this paper has demonstrated the effectiveness of the proposed method. The research 
results acquired in this paper can be served as an important reference for urban rail transit operators, and may provide some insights for the maintenance work of the key equipments in signalling system.

\section{Acknowledgements}

This work is supported by National Key Research and Development Program of the Chinese 13th Five-year plan under Grant No. 2016YFB1200602-02, 2016YFB1200400, Fund of Shanghai Cooperative Center for Maglev and Rail Transit.

\section{References}

[1] Fan, Y., Zhang, J., Nai, W. (2016) Study on Working Status Evaluation of Track Circuits in Shanghai Metro Line 2. 12th International Conference on Wavelet Active Media Technology and Information Processing (ICCWAMTIP), 408-411.

[2] Li, X. Yu, Y. (2015) Safety Assessment Methods of a Rail Transit Signal System. 5th International Conference on Transportation Engineering (ICTE), 1287-1295.

[3] Yam, R. C. M., Tse, P. W., Li, L., Tu, P. (2001) Intelligent Predictive Decision Support System for ConditionBased Maintenance. The International Journal of Advanced Manufacturing Technology, 17(5), 383-391.

[4] Sun, S. (2007) Analysis on RAMS of Rail Transit Signal System. Urban Mass Transit, (11), 66-69. (In Chinese)

[5] Gau, W. L., Buehrer, D. J. (1993) Vague Sets. IEEE Transactions on Systems Man \& Cybernetics, 23(2), 610614.

[6] Chen, S., Tan, J. (1994) A Note on Handling Multi Criteria Fuzzy Decision-Making Problems Based on Vague Set Theory. Fuzzy Sets and Systems, 67(2), 163-172.

[7] Zhou, X. G., Qiang, Z., Hu, W. B. (2005) Research on TOPSIS Methods Based on Vague Set Theory. Systems Engineering - Theory Methodology Application, 14(6), 537-541. (In Chinese)

[8] Zhou, Z., Wu, Q. Z., Peng, Y. L. (2006) TOPSIS Method for Fuzzy MCDM Based on Vague Set Theory. Mathematics in Practice \& Theory, (2), 278-283. (In Chinese)

[9] Liu, P. D., Guan, Z. L. (2009) An Approach for Multiple Attribute Decision-Making Based on Vague Sets. Journal of Harbin Engineering University, 30(1), 106-110. (In Chinese)

[10] Geng, X., Chu, X., Zhang, Z. (2010) A New Integrated Design Concept Evaluation Approach Based on Vague Sets. Expert Systems with Applications, 37(9), 6629-6638.

[11] Zhang, Q. H. (2007) Study on Similarity Measure between Vague Values (Sets). Journal of Electronics \& Information Technology, 29(8), 1855-1859. (In Chinese) 